\title{
Estado e questão agrária
}

Claus Germer*

\section{Resumo}

Este texto tem como objetivo discutir a relação 'Políticas públicas e a questão agrária', tendo como referência a teoria social marxista o materialismo histórico -, sobre a natureza e o papel do Estado.

Palavras-chave: Estado; Materialismo histórico; Socialismo; questão agrária.

State and agrarian question

\section{Abstract}

This text aims to discuss the relationship ' Public policy and the agrarian question ', with reference to the Marxist social theory historical materialism - about the nature and the role of government.

Key words: State; Historical materialism; Socialism; Agrarian question.

\section{Introdução}

Este artigo constitui um desenvolvimento, com base na exposição do autor na mesa de debates sobre o tema 'Políticas públicas e a questão agrária', tendo como referência a teoria social marxista - o materialismo histórico -, sobre a natureza e o papel do Estado. Como não está explícito no título, por ser pressuposto, deve-se esclarecer que as políticas públicas de que se trata são, em

* Professor aposentado do Departamento de Economia da Universidade Federal do Paraná.

Geosul, Florianópolis, v. 29, ESPECIAL, p 11-38, jul./dez. 2014 
GERMER, Claus. Estado e questão agrária.

princípio, as políticas praticadas pelo Estado burguês. No entanto, como o Estado socialista ${ }^{1}$ também já existiu, em sua primeira aparição histórica, durante quase um século, uma abordagem abrangente teria que incluí-lo. Isto seria especialmente importante ao se examinar a posição do Estado socialista em relação à questão agrária, tendo-se em mente a estratégia da 'aliança operáriocamponesa', que teve um papel decisivo tanto na vitória quanto na derrota do socialismo soviético.

Enquanto seu papel na vitória é bem estabelecido no registro histórico e entre os estudiosos, o mesmo não se pode dizer sobre o seu papel na derrota do mesmo. No entanto, a abordagem do Estado socialista teria que ser acompanhada de esclarecimentos sobre as diferenças dos contextos, que não caberiam nos limites do presente artigo, de modo que este aspecto da análise teve que ser omitida.

Como a natureza e o papel do Estado, no contexto do materialismo histórico, deitam suas raízes na estrutura de classes da sociedade, esta também terá que ser considerada. O artigo apóia-se, portanto, em três temas que possuem grande relevância no marxismo e, ao mesmo tempo, apresentam um caráter altamente polêmico: o Estado, a estrutura de classes e a questão agrária. Os três temas são essenciais para a exposição da concepção marxista do tema do artigo.

A exposição será dividida em quatro seções, além desta introdução. A primeira aborda o significado da expressão questão agrária; a segunda expõe os conceitos marxistas de classe social e de estrutura de classes do capitalismo; a terceira é dedicada à exposição da natureza e do papel do Estado capitalista. A quarta

1 Segundo a interpretação de Marx, geralmente seguida pelos autores marxistas, "entre a sociedade capitalista e a sociedade comunista medeia o período da transformação revolucionária da primeira na segunda (...), ao qual corresponde também um período político de transição (...)" (Marx, $\mathrm{s} / \mathrm{d}$, p. 221). Tem sido habitual denominar de socialista esta fase de transição (LÉNINE, 1985, p. 264-7), para contrastar com o comunismo, que seria o modo de produção comunista plenamente desenvolvido. 
GERMER, Claus. Estado e questão agrária.

seção examina, com base no exposto nas três anteriores, a ligação entre a questão agrária e a atuação do Estado, não tanto do ponto de vista do gasto público ou das políticas específicas, mas da posição adotada pelo Estado, no palco da luta de classes, em função da natureza da chamada "questão agrária". Para concluir, procura-se desenvolver a justificativa teórica da viabilidade econômica da estratégia básica da política do Estado burguês em relação à agricultura, exposta no artigo.

\section{A questão agrária no capitalismo}

A expressão questão agrária é a tradução de um termo alemão - Agrarfrage - que surgiu no ambiente e na literatura marxistas e socialistas europeus do final do século XIX, que melhor se traduz como problema agrário $^{2}$, porque o termo e a discussão referiam-se a um grave problema que o movimento dos trabalhadores e o movimento marxista e socialista enfrentavam na ocasião. Qual era o problema? O problema era que o socialismo que os socialistas pretendiam, especialmente quando já fundamentados na teoria de Marx, tinha como base social e principal força de luta o proletariado industrial, que foi o primeiro segmento do proletariado historicamente desenvolvido, e concentrado, naquela época, nas cidades.

Em contraposição, no entanto, a maior parte da população não era urbana ${ }^{3}$, mas rural, e no meio rural não havia um proletariado desenvolvido, porque o trabalho assalariado agrícola ainda era muito incipiente, mesmo nos países capitalistas mais

${ }^{2} \mathrm{O}$ termo composto Agrarfrage (título da obra clássica de Kautsky) é melhor traduzido por "problema agrário" do que por "questão agrária", pois o termo Frage, embora também signifique questão - que também possui diversos significados em português -, em Agrarfrage refere-se antes a um problema que a agricultura representava para o movimento socialista.

3 "Na Europa de 1871, o proletariado não constituía a maioria do povo em nenhum país do continente" (LÉNINE, 1985, p. 220). Mas a industrialização e a urbanização avançaram celeremente até as vésperas da I Guerra Mundial (MOMMSEN, 1975, p. 35-57). 
GERMER, Claus. Estado e questão agrária.

desenvolvidos da Europa Ocidental. A incipiência do trabalho assalariado na agricultura implica que nela ainda sobreviviam relações de produção anteriores ao capitalismo ${ }^{4}$. A população rural compunha-se, principalmente, daquilo que hoje ainda se denomina - em muitos casos de modo impróprio, como ocorre no Brasil -, de campesinato, referindo-se à figura do agricultor independente ou semi-independente, mas em transição para a independência, originado nos servos da gleba dos feudos, unidade política e econômica básica do feudalismo.

O que já existia no meio rural, como resultado do desenvolvimento do capitalismo, era a figura do semi-assalariado, de resto muito comum nas fases iniciais da agricultura capitalista ${ }^{5}$, inclusive no Brasil, onde existe até hoje em medida ainda considerável, embora dentro dos limites de uma população rural já bastante rarefeita. $\mathrm{O}$ semi-assalariamento é apenas o primeiro passo para o assalariamento pleno. Sendo assim, o que resultava disso no contexto da luta de classes pelo socialismo? Resultava que o proletariado, força propulsora da revolução socialista, representava, na realidade, uma minoria dentro do conjunto da sociedade. Mesmo onde fosse maioria nas cidades, a população urbana era relativamente pequena, isto é, proporcionalmente menor do que a população rural, sendo a única exceção, naquela época, a Inglaterra, onde a população urbana já era maioria em relação à população rural.

Pois bem, os socialistas, que naquela época se organizavam e procuravam organizar o próprio proletariado, não possuíam

4 "Ora, o que mais nos ocupa atualmente é o papel das formas précapitalistas e não capitalistas da agricultura no interior da sociedade capitalista" (KAUTSKY, 1968, p. 17).

${ }^{5}$ Segundo Lênin, com base em dados da época, "o operário agrícola dotado de um pedaço de terra é um tipo próprio a todos os países capitalistas, variando conforme as condições nacionais" (LÊNIN, 1982, p. 116). 
GERMER, Claus. Estado e questão agrária.

inserção no meio rural, estando organizados apenas no meio urbano. E ocorreu um episódio político da maior importância e que explicitou de modo dramático o problema constituído pela condição minoritária do proletariado industrial. Este episódio foi a Comuna de Paris, de 1871, em que o proletariado de Paris conseguiu conquistar e manter o poder durante pouco mais de dois meses, e os comunardos, como são chamados os integrantes da Comuna, tinham a expectativa de que os pobres do campo viessem em auxílio dos pobres da cidade, juntando-se aos mesmos no empreendimento de conquistar e consolidar o poder. Mas isso, por diversos motivos, não aconteceu, e desta circunstância retirou-se um ensinamento político decisivo, ao qual me referirei em seguida.

O que se deve neste momento destacar é o fato de que o problema agrário, representado pela expressão "questão agrária", residia na circunstância de o proletário industrial ser então minoritário, de modo que precisaria, para poder ser vitorioso, organizar-se no meio rural, como a Comuna de Paris havia demonstrado, a fim de que o proletariado tivesse, numérica e politicamente, uma expressão maior na sociedade. Este objetivo, no entanto, defrontava-se com um contexto bastante complexo na agricultura, que os próprios socialistas não conheciam suficientemente, sendo necessário que o estudassem. A estas necessidades procuraram responder as obras de Kautsky (1968) e Lênin (1982), cuja obra, porém, ultrapassa o âmbito do problema agrário.

\section{A estrutura de classes do capitalismo}

Os membros de uma sociedade podem ser divididos nas mais variadas categorias, segundo diversos critérios, cada um relevante para o objetivo que, em cada caso, se tem em vista. Se o objetivo é identificar os elementos que constituem os fundamentos estruturais da sociedade, ou a sua base material, o critério fundamental consiste em identificar a inserção de cada um nas 
GERMER, Claus. Estado e questão agrária.

relações de produção ${ }^{6}$. As relações de produção são as relações estruturais que se estabelecem entre os membros da sociedade na produção da sua vida, e estas refletem a forma objetiva de apropriação dos meios de produção, a qual por sua vez se expressa na forma jurídica da propriedade. Disto resulta que os agrupamentos que compõem a sociedade têm por base a relação dos membros de cada agrupamento com a propriedade dos meios de produção. Estes agrupamentos são as classes sociais, e esta divisão é a mais relevante porque as classes constituem os fundamentos objetivos de toda a estrutura social.

O capitalismo é uma sociedade baseada na propriedade privada dos meios de produção, do que resulta que ela se divide em duas grandes classes fundamentais, os proprietários dos meios de produção e os não proprietários. Note-se que a propriedade privada, aqui mencionada, refere-se à propriedade dos meios de produção e não dos meios de consumo, categorias que são frequentemente confundidas quando se fala em propriedade privada. Os meios de produção é que são decisivos, porque compreendem os elementos materiais necessários à produção das coisas essenciais à reprodução cotidiana da vida dos indivíduos e da sociedade. A qualidade e a quantidade dos meios de consumo são determinadas pela qualidade e quantidade dos meios de produção, que são portanto os elementos materiais de base da estrutura social.

É comum imaginar-se que a propriedade privada significa que a propriedade dos bens, ou da riqueza, é distribuída mais ou menos igualmente entre os membros da sociedade. Mas não é esse o significado da propriedade privada, do ponto de vista social. Como já exposto, trata-se da propriedade dos meios de produção, não dos meios de consumo. Na evolução da sociedade, a fase inicial é caracterizada pela propriedade coletiva dos meios de produção, que pertencem portanto a todos em comum. A fase

6 "O conjunto d[as] relações de produção constitui a estrutura econômica da sociedade, a base concreta sobre a qual se eleva uma superestrutura jurídica e política ..." (MARX, 1977, p. 24). 
GERMER, Claus. Estado e questão agrária.

seguinte é profundamente transformada pelo surgimento da propriedade privada, pois este acontecimento implica que os meios de produção, até então coletivos, são açambarcados por uma parte da sociedade, sendo todos os demais - geralmente a maioria excluídos de tal propriedade e do acesso aos meios de produção, fundamentais à sua sobrevivência.

O que decide o destino dos indivíduos e das classes sociais é a propriedade dos meios de produção, que são os fatores materiais da produção de riqueza. Consequentemente, ao surgir historicamente, a propriedade privada deu origem a uma sociedade dividida, fundamentalmente, em duas classes. A lógica profunda desse sistema consiste em tornar possível a exploração da força de trabalho da classe não proprietária pela classe proprietária, o que se detalhará adiante.

As duas classes fundamentais citadas não são simétricas em termos quantitativos. Como resultado de condicionamentos econômicos, a classe proprietária é sempre muito reduzida, enquanto a classe não proprietária engloba a maioria da população. De modo geral a classe proprietária, que no capitalismo é a classe capitalista, também chamada, sociologicamente, de burguesia, compreende menos de cinco por cento da população. Não há nenhum país capitalista em que a classe capitalista alcance os cinco por cento ${ }^{7}$.

De modo geral, o indicativo do grau de desenvolvimento social, em termos históricos, é a proporção da classe trabalhadora, isto é, dos não-proprietários de cada modo de produção, que no capitalismo são os assalariados. Isto significa que, quanto mais desenvolvido o capitalismo em um país, maior é a proporção da classe dos trabalhadores assalariados na sua população. Nos EUA, país onde o capitalismo encontra-se no estágio mais avançado de desenvolvimento,

7 " Em todos os modos de produção a classe proprietária constitui uma minoria muito reduzida, devido aos condicionamentos econômicos já citados. No feudalismo as proporções parecem ter sido idênticas ao capitalismo. Na França feudal, por exemplo, a aristocracia, que era a classe proprietária do feudalismo, compreendia apenas cerca de $4 \%$ da população no momento da revolução de 1789 (SOBOUL, 1974, p. 16). 
GERMER, Claus. Estado e questão agrária.

os assalariados já são mais de noventa por cento da população. No Brasil, segundo os censos demográficos de 2000 e 2010, a classe capitalista representa apenas cerca de $3 \%$ da população, enquanto os assalariados representam cerca de $75 \%$. Sendo assim, é compreensível que o confronto político fundamental no capitalismo se dê entre essas duas classes polarizadas, a burguesia e o proletariado. O que impressiona é que uma classe tão diminuta como a classe proprietária, compreendendo menos de cinco por cento da população, consiga dominar uma maioria tão esmagadora. Isso necessita explicação, que não é simples, parte da qual será exposta na seção seguinte.

Significativo para os propósitos deste artigo é que, entre as duas classes fundamentais citadas existe uma terceira da maior relevância, que no entanto não é propriamente uma classe, mas um segmento de classe, porque integrante da burguesia. Esta terceira classe é a pequena burguesia $^{8}$. O motivo de se distinguir a pequena burguesia da burguesia é principalmente político, e requer explicação.

O que caracteriza os membros da pequena burguesia é que são, geralmente, menores capitalistas, isto é, detentores de menores capitais, motivo pelo qual tendem a ser derrotados pelos maiores na concorrência. A concorrência (FINE, 1988, p. 74) é uma característica fundamental do capitalismo, e refere-se ao fato de que as empresas lutam umas com as outras pela sobrevivência, no mercado. E o mercado, no capitalismo, possui uma lógica específica, neste aspecto, expressa na lei da centralização de capitais, que significa que, no decorrer da evolução e com base na concorrência, os capitais aumentam gradualmente as suas escalas ou dimensões, principalmente através da incorporação das empresas menores pelas maiores (MARX, 1984, cap. 23). Assim, as empresas menores - e muitas vezes até

${ }^{8}$ Pequena burguesia não é o mesmo que classe média. Classe média é um conceito um tanto vago, baseado em faixas de rendimentos, não na propriedade dos meios de produção, que é o fundamento da existência das classes sociais, motivo pelo qual a utilização do termo 'classe', em 'classe média', é teoricamente impróprio. São, portanto, dois conceitos distintos: classes sociais não são faixas de rendimento. 
GERMER, Claus. Estado e questão agrária.

mesmo grandes empresas -, são absorvidas pelas maiores. Por exemplo, na última crise econômica mundial, que irrompeu em 2008, a Perdigão absorveu a Sadia, embora a Sadia fosse a maior das duas, na época. Esta crise forneceu muitos outros exemplos deste tipo em todo o mundo. Mas a regra mais geral é que empresas grandes absorvam empresas menores. Isto tem uma importante consequência, expressa em um processo sistemático e contínuo no qual as empresas pequenas e médias vão sendo destruídas pela concorrência, indo à falência e sendo absorvidas pelas maiores.

Estes exemplos facilitam o entendimento da natureza da pequena burguesia e da sua importância política. A pequena burguesia é o conjunto de capitalistas que, no contexto da concorrência entre grandes e pequenas empresas, têm dificuldade, ou não têm condições, de manter suas empresas viáveis, motivo pelo qual sentem-se continuamente ameaçados de falência. Isto significa que, do ponto de vista econômico, estão abaixo da linha de sobrevivência das empresas. Por esse motivo, pelo fato de terem continuamente uma perspectiva concreta de falir, estes pequenos capitalistas desenvolvem uma visão política crítica da centralização do capital, também denominada monopolização, e reclamam dos governos políticas de controle dos monopólios e oligopólios. O seu discurso, muitas vezes radical, adota uma terminologia crítica do próprio capitalismo e mesmo do imperialismo. Mas a posição anti-imperialista geralmente não é mais do que uma oposição à existência, no país, de grandes empresas estrangeiras que concorrem com as nacionais, geralmente menores, e as destroem e absorvem. No entanto, apesar de tomar posições frequentemente radicais, a pequena burguesia não se opõe ao capitalismo, e também não é socialista nem a favor do proletariado. $\mathrm{O}$ que ela pretende é um impossível capitalismo sem concorrência, um capitalismo em que ela possa sobreviver. Isto, no entanto, geralmente não é fácil de perceber, o que torna essencial um esclarecimento.

$\mathrm{O}$ que é significativo é que, nos momentos de acirramento da concorrência e do risco de falência, por exemplo numa crise econômica, quando empresas pequenas e médias vão à falência em maior número, a pequena burguesia radicaliza-se politicamente. Seus 
GERMER, Claus. Estado e questão agrária.

representantes podem chegar até mesmo a utilizar, nos seus discursos, um linguajar socialista, inclusive termos marxistas, dando a impressão de serem, também, anticapitalistas. O problema político que isto representa para os trabalhadores é que este discurso radicalizado pode atrair, e atrai, uma parte dos mesmos, pois o discurso pequenoburguês penetra mais facilmente entre a população, devido ao maior poder econômico e midiático, e consequentemente político, dos seus representantes. Assim atraídos, os trabalhadores, ao invés de lutar pelo que é do seu interesse, que é o socialismo -considerando que, para eles, o capitalismo, mesmo pequeno-burguês, não oferece futuro desviam-se para uma luta que não é deles e não resolve os seus problemas. Esta mesma característica confere à pequena burguesia uma importância estratégica na luta de classes, especialmente após a I Guerra Mundial, que é essencial ao entendimento do caráter das políticas do Estado - em particular das políticas agrárias, tema deste artigo -, como se procurará esclarecer adiante.

\section{O Estado e o capitalismo}

Frequentemente concebe-se o Estado como uma instituição acima da sociedade, uma espécie de órgão imparcial, regulador da vida social, ou como uma instituição no interior da qual os diferentes grupos de interesses se enfrentam e disputam espaços. A concepção marxista difere frontalmente destas e, na sua elaboração, apoia-se na evidência história da gênese do Estado e na explicação teórica do seu papel objetivo na sociedade. Historicamente, o Estado surge com a emergência da propriedade privada $^{9}$, o que sugere que nesta resida a sua explicação teórica ${ }^{10}$. É necessário, portanto, partir desta.

9 Deve-se a Engels, em obra pioneira, a exposição do processo de emergência da propriedade privada e do Estado a partir da comunidade primitiva, esta baseada na propriedade comum dos meios de produção, por isto denominada comunismo primitivo (ENGELS, 1980).

${ }^{10}$ A propriedade privada, fundamento das relações de produção específicas dos modos de produção nela baseados, possui também uma gênese 
GERMER, Claus. Estado e questão agrária.

Com efeito, como já mencionado, a lógica que preside a estrutura de classes que opõe proprietários e não-proprietários, consiste no fato de que a divisão em classes constitui a base e a condição que torna possível o processo de exploração dos não-proprietários pelos proprietários. Como os não-proprietários estão privados de meios de produção, através dos quais poderiam produzir seus meios de subsistência, evidentemente não sobreviveriam se lhes fosse definitivamente vedado acesso a eles, nem é este o sentido da propriedade privada. Assim, qual é a relação que se estabelece entre as duas classes? A classe proprietária permite aos não-proprietários o acesso aos meios de produção para que possam produzir seus próprios meios de vida, mas em troca exige deles, por assim dizer, o pagamento de um pedágio, que consiste em produzir, além dos seus próprios meios de vida, também os meios de vida da classe proprietária e os demais meios necessários à manutenção de toda a estrutura de sustentação que essa classe elabora (MARX, 1983, cap. 7; HIMMELWEIT,1988).

Essa exploração, que pode atingir graus de intensidade muito significativos, caracteriza todas as sociedades baseadas na propriedade privada, desde o escravismo, passando pelo feudalismo e agora no capitalismo. Apenas o mecanismo específico é diferente. Mas a exploração tem consequências. A relevante ao presente tema é que os explorados não se deixam explorar passivamente, mas reagem contra a exploração, devendo ser submetidos ao conformismo pela força e sistematicamente. A classe proprietária necessita, portanto de uma instituição de controle da classe nãoproprietária. Necessita, especificamente, de uma instituição coletiva,

histórica, isto é, como todos os fenômenos sociais, é não-intencional, isto é, emerge espontaneamente como fruto da prática repetida do trabalho social, que eleva as forças produtivas a um nível de desenvolvimento que cria as condições e a necessidade para a emergência da propriedade privada. Permito-me remeter o leitor a um artigo em que exponho extensamente a minha interpretação deste importante ponto (GERMER, 2009). 
GERMER, Claus. Estado e questão agrária.

e não individual; permanente, e não temporária. Esta instituição é o Estado $^{11}$ (LÉNINE, 1985, p. 191-194).

Como concentração do poder social, o Estado também desempenha, paralelamente às funções relacionadas ao domínio de classe, outras funções, de natureza técnica, indispensáveis à manutenção e regulação das condições básicas da reprodução do coletivo social e resultantes do caráter de cada sociedade ${ }^{12}$. Mas a conexão destas funções técnicas ao ente político que é o Estado é apenas decorrência da concentração do poder social nas mãos da classe proprietária. Abolida a propriedade privada e, consequentemente, tornado desnecessário o Estado, tais funções seriam realizadas por uma autoridade puramente administrativa. O que confere a esta autoridade, no capitalismo, o caráter político do Estado e constitui a sua essência, é a captura do poder social por uma classe e sua utilização para o controle da classe não-proprietária.

Ao observador superficial os trabalhadores atuais podem parecer perfeitamente ajustados ao trabalho assalariado e conformados com as condições impostas pelos empregadores. Mas isto é apenas a aparência. Também neste caso é necessário identificar a gênese histórica e a explicação teórica do fenômeno observado a olho nú. Assim, se o observador examinar as leis - e a sua evolução histórica - que presidem a relação capital-trabalho, e se a observação penetrar além da aparência e focalizar o interior das empresas, das fábricas, bancos, supermercados, shoppings, etc, verá em funcionamento um mecanismo refinado e contínuo de repressão, dotado de ampla base legal, que faz com que qualquer tentativa de insubordinação seja imediatamente punida, de formas

11 "O Estado moderno é apenas um comitê que administra os negócios comuns de toda a classe burguesa" (MARX/ENGELS, 1989, p. 40).

12 "(...) o trabalho de superintendência e ingerência do governo em todos os aspectos compreende ambas as coisas: tanto a execução das tarefas comuns, que derivam da natureza de toda comunidade, como as funções específicas, que provêm da antítese entre o governo e a massa do povo" (MARX, 1984b, p. 286). 
GERMER, Claus. Estado e questão agrária.

as mais diversas. Tratando-se de um indivíduo com certa liderança, poderá ser demitido e inscrito na lista negra das empresas e dificilmente conseguirá novo emprego, pelo menos nas proximidades de onde vive. Em síntese, ultrapassada a aparência enganosa do conformismo, o observador rigoroso depara-se com o trabalhador enredado e imobilizado em uma complexa teia legalrepressiva permanente que o intimida e subjuga, cujos fios convergem para o Estado como representante do empregador.

\section{A questão agrária e as políticas públicas}

$\mathrm{Na}$ época em que o problema agrário se manifestou, na Europa, o campesinato - principal segmento da pequena burguesia era tradicionalmente aliado da burguesia, e assim permaneceu até o fim do século 19, porque a Revolução Francesa, liderada pela burguesia, o havia libertado do jugo feudal (SOBOUL, 1974, p. 109112). Embora o capitalismo já estivesse consideravelmente desenvolvido na França, antes da revolução de 1789, o processo de libertação dos servos da gleba dos nobres feudais aos quais serviam, processo do qual emergia o campesinato, era um processo doloroso e prolongado, então ainda em curso. O camponês era liberado, aos poucos, de algumas obrigações, mas à custa de assumir outras, principalmente em dinheiro, o que o submetia crescentemente ao mercado ou ao trabalho assalariado a fim de obter dinheiro para o pagamento de tais obrigações. O camponês deixava, por exemplo, de ser obrigado a trabalhar tantos dias por ano gratuitamente para o nobre feudal mas, em compensação, assumia o compromisso de pagar uma determinada prestação, geralmente significativa, em dinheiro. Neste processo a renda em trabalho, forma original da servidão, convertia-se gradualmente na forma capitalista da renda, a renda em dinheiro (MARX, 1985, cap. 47).

A revolução francesa libertou de um só golpe o campesinato desta espoliação, não só na França mas também nos países nos quais a influência da revolução incendiou as lutas antimonarquistas e anti-feudais, ou que a França ocupou durante as 
GERMER, Claus. Estado e questão agrária.

guerras resultantes da agressão das potências monárquicas européias, que se coligaram para invadir a França a fim de sufocar a revolução (SOBOUL, 1974, p. 116; MANFRED, 1966, p. 113119). Aconteceu, no entanto, o contrário. A França reagiu e conquistou praticamente toda a Europa ocidental e, nas regiões conquistadas, fomentou as mesmas mudanças, com maior ou menor grau de intensidade conforme as circunstâncias locais. Com isso estabeleceu-se um compromisso do campesinato com a burguesia, à qual aquele permaneceu aliado ao longo de todo o século XIX, período no qual diversos episódios revolucionários se sucederam, estendendo ou mesmo completando o alcance da revolução burguesa. Mas o campesinato aliou-se à burguesia não só contra a aristocracia feudal, mas também, por ação ou omissão, contra as tentativas de conquista de direitos pelo proletariado. Esta situação persistiu até o início do século XX, às vésperas da revolução russa.

Foi Lênin, em parte inspirado pela Comuna de Paris ${ }^{13}$, quem desenvolveu a estratégia capaz de resolver o desafio representado pelo problema agrário para o proletariado em luta pelo socialismo, isto é, pelo caráter minoritário do proletariado industrial no conjunto da população. Esta estratégia foi a aliança operário-camponesa. A Rússia era o mais atrasado país europeu, do ponto de vista das relações sociais. De cerca de 130 milhões de habitantes, na época da revolução, cerca de 100 milhões eram, na maior parte, pequenos camponeses, sujeitos ainda a obrigações feudais significativas, mas onde, na parte final do século XIX, especialmente a partir do fim do feudalismo, em 1861, o capitalismo penetrou com muita rapidez, expressando-se na progressiva proletarização do campesinato e no crescimento de uma

13 "(...) deve-se considerar que Lênin pertenceu a uma geração que amadureceu politicamente após a catástrofe da Comuna de Paris. A incapacidade dos operários de Paris, de atraírem para o seu lado os camponeses franceses, foi o fator decisivo que colocou o regime burguês de Versalhes em condições de derrotar a Comuna em maio de 1871. Uma tal derrota política arraigou-se na memória [dos socialistas - CMG]" (North). 
GERMER, Claus. Estado e questão agrária.

camada de semi-assalariados, constituindo um semi-proletariado que Lênin denominou de "proletários com lote", como já mencionado. Isto significa que estes trabalhadores ocupavam-se em parte na sua própria área e na outra parte se assalariavam junto a agricultores maiores, os camponeses ricos, ou em empregos urbanos nas aldeias e cidades. A estratégia da aliança operário-camponesa, proposta por Lênin, consistia na aliança entre o proletariado urbano e o semi-proletariado rural ou seja, o segmento mais pobre do campesinato, em processo de proletarização, estratégia que se revelou bem-sucedida e foi uma das condições da vitória da Revolução Russa.

Uma precisão é necessária no conceito da aliança operáriocamponesa, no que se refere ao termo camponesa, a fim de evitar uma confusão muito comum, que se presta à justificação de alianças políticas espúrias do proletariado com segmentos da pequena burguesia. A concepção leniniana desta aliança assume dois significados, correspondentes às duas fases da revolução - a fase burguesa e a fase socialista -, que foram explicitados por Lênin já antes da revolução. As duas fases justificam-se devido à sobrevivência de fortes elementos do feudalismo e da própria aristocracia feudal na Rússia, o que caracteriza a primeira fase da revolução como burguesa. Nesta fase o proletariado deveria aliar-se com toda a burguesia incluindo a burguesia camponesa - contra a aristocracia feudal e as heranças feudais remanescentes. Mas a aliança operário-camponesa é concebida, já nesta fase, como a aliança dos elementos proletários da sociedade: o proletariado industrial e o semi-proletariado do campo, este representado apenas pela camada mais pobre, composta, na maioria, de 'proletários com lote', que se alia à burguesia na revolução burguesa contra a aristocria, mas se opõe a toda a burguesia na segunda fase, da revolução socialista.

Relevante para o tema do presente artigo é o fato de a Revolução Russa ter sido seguida, na Europa, por erupções revolucionárias do mesmo tipo, após o término da I Guerra mundial. A Revolução Russa deu-se em 1917, a guerra terminou em 1918, e logo em seguida ocorreu, na Alemanha, a mais importante destas erupções revolucionárias, que por pouco não foi 
GERMER, Claus. Estado e questão agrária.

vitoriosa $^{14}$. O país experimentou um período marcado por intensa luta de classes, que se estendeu até 1923 e se encerrou com a derrota da revolução. Mas os socialistas conseguiram conquistar o poder, por alguns meses, em algumas cidades importantes, devendo-se a eles, inclusive, a proclamação da república na Alemanha, que até então ainda era uma monarquia.

\subsection{O Estado e a questão agrária}

Qual foi o impacto da Revolução Russa e das tentativas que se seguiram, sobre as políticas praticadas pelo Estado capitalista a partir de então? A vitória baseada em uma aliança operário-camponesa acendeu a luz vermelha no painel de controle das burguesias européias e, por extensão, também da estadunidense, pois na revolução russa o campesinato abandonou o apoio até então dado à burguesia e alinhouse ao proletariado, abrindo um precedente que poderia ser fatal ao poder burguês. Tornou-se vital, portanto, recuperar o apoio do campesinato, o que se fez por intermédio da execução de políticas públicas - em diversas áreas - destinadas a proteger a pequena burguesia rural - o campesinato -, da falência, políticas que se estenderam também aos segmentos urbanos desta classe. A burguesia passou a praticar ao inverso a estratégia da aliança operáriocamponesa que dera a vitória aos bolcheviques na Rússia, ou seja, a burguesia adotou uma estratégia explícita de aliança burguesacamponesa, frequentemente justificada pelo papel conservador das 'classes médias' agrárias. O fundamento de tais políticas consiste na intenção, em primeiro lugar, de evitar a radicalização da pequena burguesia rural diante do estado de sempre iminente proletarização dos seus membros e, em segundo lugar, de evitar a constituição, na agricultura, da oposição de classes entre capitalistas e assalariados, da qual emerge o radicalismo proletário e sua inclinação ao socialismo.

Deve-se notar que há uma diferença substancial entre esta situação e a prevalecente durante o século 19, de apoio do

14 Para uma exposição resumida deste importante episódio sugere-se consultar Loureiro (2005). 
GERMER, Claus. Estado e questão agrária.

campesinato às burguesias europeias. Neste caso não havia aliança formal, o que havia era simples submissão do campesinato à direção burguesa, geralmente de modo espontâneo e, quando não, pela violência. Isto se deve ao fato de que, durante a maior parte do século 19, a burguesia manteve caráter revolucionário, que, entretanto, começou a declinar a partir das revoluções burguesas de 1848, quando o proletariado - até então também caudatário da direção burguesa - pela primeira vez apresentou-se na cena política de modo independente - e ameaçador -, o que conduziu a burguesia à conciliação com os segmentos remanescentes da aristocracia feudal. Após a revolução russa a busca do apoio da pequena burguesia agrária tornou-se consciente e formal.

As políticas públicas são geralmente entendidas como as linhas de ação práticas - gerais ou dirigidas a setores específicos - dos governos. Aqui, no entanto, trata-se de examinar não o governo entendido como mero órgão executivo do Estado e sujeito a alternância contínua -, mas o próprio Estado, como ente político representativo da classe proprietária e seus interesses, e a sua estratégia geral permanente no cenário das lutas de classes no período considerado. A revolução russa colocou no cenário político, como entes expressivos, não só a pequena burguesia rural, mas principalmente o proletariado revolucionário, alvo principal da estratégia burguesa. Neste artigo, no entanto, o foco situa-se na pequena burguesia rural. Enquanto em relação ao proletariado a estratégia foi de confronto, no caso da pequena burguesia rural o objetivo foi - e ainda é - segundo se depreende, de neutralização e atração para a causa da burguesia. Para tanto, seria necessário eliminar, ou pelo menos amenizar, a constante ameaça de falência que a assombrava desde o final do século 19, em particular na Europa, o que implica estabilizar a sua situação econômica através de políticas de proteção dos mais diversos tipos: limitação da área possuída pelo agricultor; concessão de subsídios fiscais, tarifários, creditícios, de preços; fomento da pesquisa e assistência técnica estatais; proibição de atuação de sociedades anônimas na agricultura; regularização fundiária e/ou reforma agrária; eletrificação rural, entre outras. 
GERMER, Claus. Estado e questão agrária.

Exemplo expressivo destas políticas é o PAC europeu, isto é, a Política Agrícola Comum, na Europa, que absorve parcela muito significativa do orçamento europeu, aplicada anualmente no subsídio aos pequenos agricultores. Ao mesmo tempo, na Europa e nos EUA, foram instituídos por lei limites máximos de área possuída no meio rural, de tal modo que o proprietário rural não pode possuir uma área superior ao limite estabelecido. Aqui mesmo, no Brasil, volumosos subsídios ao crédito rural impulsionaram a modernização técnica e econômica da agricultura capitalista brasileira a partir do final dos anos 1960, especialmente nos anos 1970, estabelecendo condições especiais para pequenos agricultores, na época chamados 'baixa renda'.

Nos EUA proibiu-se, por leis estaduais, a atuação de sociedades anônimas na agricultura. Isso não tem impedido inteiramente, no entanto, que esses pequenos agricultores continuem saindo da agricultura, sendo absorvidos por produtores maiores e migrando para as cidades, o que apenas reflete a vigência da lei da centralização, embora atenuada, a despeito das políticas estatais. De qualquer modo, a estratégia do Estado em relação à pequena burguesia rural, aliada às demais políticas de combate ao socialismo, atingiu em larga medida o seu objetivo na agricultura: gerou uma estrutura produtiva com predomínio da produção em pequena/média escalas e submeteu a migração rural-urbana a um controle razoável nos países capitalistas avançados.

\subsection{Fundamento econômico da aliança burguesa-camponesa ${ }^{15,16}$}

A execução de uma política agrária destinada a proteger a pequena burguesia rural implica em manter, na agricultura, uma

${ }^{15}$ Melhor seria denominá-la aliança burguesa/pequeno-burguesa, devido à impropriedade do uso do termo camponês em contextos pós-feudais, mas mantém-se como contraste ao sentido político da expressão aliança operário-camponesa.

${ }^{16}$ Esta seção constitui, em boa medida, uma extensão de artigo anterior (GERMER, 2002). 
GERMER, Claus. Estado e questão agrária.

estrutura econômica de pequenas/médias empresas, isto é, de produção em pequena/média escalas. Isto conflita claramente com a tendência, natural e necessária no capitalismo, à centralização dos capitais, ou seja, ao aumento das escalas de produção, que é uma condição e uma consequência, ao mesmo tempo, da tendência também necessária de elevação gradual da produtividade do trabalho. Caracterizar tal tendência como natural e necessária significa que a mesma corresponde à lógica interna do capitalismo, o que implica também que corresponde ao desenvolvimento progressivo das forças produtivas. Ora, este desenvolvimento expressa as forças dinâmicas mais poderosas e dominantes em qualquer modo de produção, especialmente no capitalismo, e não pode, por esta razão, ser detido, embora possa ser obstaculizado, como se esclarecerá adiante. Consequentemente, não se pode admitir que o Estado burguês possa, a fim de manter o poder, deter o desenvolvimento das forças produtivas em uma esfera tão importante quanto a agricultura.

Com efeito, o expressivo desenvolvimento tecnológico que se observa na agricultura, tanto nos países europeus sob a égide do PAC, quanto, principalmente, nos EUA, cuja agricultura ainda é dominada, em larga medida, pelo que se denomina 'family farm', cujas escalas de produção são condicionadas, entre outras, por limitações legais da área máxima por agricultor, indica que a estrutura da produção agrícola, caracterizada pelo predomínio da produção em pequena/média escalas, não parece constituir obstáculo ao desenvolvimento das forças produtivas e da produtividade do trabalho, a taxas compatíveis com as exigências da economia como um todo. Há, portanto, uma contradição que necessita ser explicada, pois o desenvolvimento das forças produtivas não pode ser interrompido arbitrariamente, como já afirmado, mesmo pelos detentores do poder de Estado. Como isto efetivamente parece não ter ocorrido, deve-se concluir, em primeiro lugar, que a contenção do crescimento das escalas de produção na agricultura é possível, sem entrar em conflito com o desenvolvimento das forças produtivas e a elevação da 
GERMER, Claus. Estado e questão agrária.

produtividade do trabalho; em segundo lugar, se é assim, deve-se admitir a existência, na agricultura, de características técnicas particulares a ela, que tornam possível assegurar o aumento da produtividade do trabalho, mesmo em escalas de produção relativamente pequenas, compatíveis com o aumento médio da produtividade na economia como um todo.

A hipótese deste artigo é que a razão fundamental para isto reside na dependência da agricultura de leis biológicas ${ }^{17}$, no aspecto específico de que altera a configuração da divisão técnica do trabalho, ou seja, da divisão do trabalho no interior das unidades de produção, um dos fatores fundamentais da elevação da produtividade do trabalho. Uma comparação com a indústria de transformação facilita a exposição do argumento. Nesta indústria, digamos de calçados, a fabricação do produto pode percorrer uma linha de produção, em que, simplificando, cada trabalhador recebe do anterior o produto em elaboração e realiza a operação que lhe cabe, passando-o em seguida ao trabalhador seguinte, que realiza outra operação e passa o produto adiante, e assim sucessivamente, até que o produto esteja terminado ${ }^{18}$. Isto significa que o produto em elaboração encontra-se em todas as fases da produção $a o$ mesmo tempo, ou seja, pode-se observar, no mesmo momento, todas as operações do processo produtivo sendo realizadas simultaneamente, desde a primeira operação até o produto final acabado. Esta divisão de trabalho, isoladamente, dota o trabalho de

17 Esta afirmação não coincide com a opinião, difundida entre pesquisadores da agricultura ligados à ideologia pequeno-burguesa da "agricultura familiar", em época não muito distante, de que o capitalismo não poderia desenvolver-se na agricultura devido à sua dependência das leis biológicas. Já Ricardo, há duzentos anos, criticou sarcasticamente a opinião de Adam Smith - que tinha no entanto outro sentido -, mostrando que diversos ramos da indústria são também estritamente dependentes das leis biológicas, o que nem por isto cria qualquer obstáculo ao pleno domínio da lógica capitalista (RICARDO, 1975, p. 82-85).

18 Para simplificar, supõe-se inicialmente uma produção do tipo manufatureiro (MARX, 1983, cap. 12). 
GERMER, Claus. Estado e questão agrária.

capacidades que aumentam extraordinariamente a sua
produtividade, em comparação com o artesanato, no qual o artesão, sozinho, realiza todas as operações sucessivas da produção, como já Adam Smith demonstrou (SMITH, 1983, cap. 1).

$\mathrm{Na}$ agricultura a simultaneidade das operações sucessivas é impossível, e é a esta circunstância que Smith atribuiu o que considerou ser a crônica menor produtividade do trabalho neste setor. Não se pode semear e colher ao mesmo tempo, ou ao mesmo tempo preparar o terreno e combater pragas e doenças. Cada operação deve aguardar o desenvolvimento do ciclo biológico do solo e da planta (ou animal), de modo que as operações só podem ser realizadas em sequência cronológica e não simultaneamente. Smith - e os economistas posteriores -, no entanto, parece não ter percebido uma circunstância, que seria decisiva, segundo a qual a agricultura se diferencia do artesanato ${ }^{19}$ e se iguala à indústria de transformação: no artesanato o artesão elabora cada unidade do produto do começo ao fim, passando por todas as operações, e repete o mesmo processo em cada uma das unidades produzidas, enquanto na indústria manufatureira cada trabalhador realiza uma só operação em toda a massa de produtos em elaboração, fluindo na linha pelas suas mãos.

$\mathrm{Na}$ agricultura, as operações sucessivas também são realizadas - graças à sua separação cronológica devida ao condicionamento biológico -, tal como na indústria manufatureira, por um ou mais trabalhadores em toda a massa do produto em elaboração, ao invés de as operações sucessivas serem realizadas em sequência em cada unidade do produto. Devido a isto, o trabalho agrícola apresenta a característica fundamental da divisão manufatureira do trabalho que tornou possível a invenção e o uso de máquinas: o trabalhador, agindo sobre toda a massa da produção na operação que lhe cabe, realiza repetidamente apenas um ou

19 O artesanato, em que o produtor trabalha sozinho, é a forma de produção típica do feudalismo e a primeira forma da produção industrial, seguida, no capitalismo, pela manufatura e a indústria mecanizada (MARX, 1983, cap.12). 
GERMER, Claus. Estado e questão agrária.

poucos movimentos simples, capazes de serem realizados por aparatos mecânicos. Este foi um dos fatores que tornaram possível a invenção da máquina, carro-chefe da Revolução Industrial iniciada na segunda metade do século 18.

Portanto, a circunstância decisiva, que diferencia a agricultura da indústria, reside no fato de que as operações sucessivas, em consequência do condicionamento biológico, não podem ser realizadas simultaneamente na agricultura. Se isto fosse possível, o contingente de trabalhadores agrícolas concentrados em uma mesma unidade, poderia crescer do mesmo modo que na indústria $^{20}$. Isto não impede, porém, que, com o desenvolvimento da mecanização agrícola, graças à característica que iguala a agricultura à indústria, exposto acima, máquinas sejam introduzidas na realização de cada operação, permitindo, em cada uma delas e no conjunto, a elevação da produtividade do trabalho de modo análogo ao que ocorre na indústria, embora talvez não nas mesmas proporções (isto a esclarecer por pesquisa específica).

Esta particularidade da agricultura exige que se recorra à distinção entre duas definições do conceito de escala de produção, a escala absoluta e a escala relativa. A escala absoluta designa a dimensão absoluta da produção, isto é, a sua dimensão física total, enquanto a escala relativa mede a dimensão da produção em relação à força de trabalho empregada. O que as políticas agrárias até agora mencionadas têm conseguido é conter a escala absoluta. A definição que interessa a este ponto, porém, é a escala relativa que, teoricamente, denomina-se composição técnica do capital (MARX, $1984 \mathrm{a}$, p. 187), representada pela equação $\mathrm{q}_{\mathrm{t}}=\mathrm{MP} / \mathrm{FT}$, ou seja, a

${ }^{20}$ Seria como se diversas áreas de produção, digamos de soja, pudessem ser sobrepostas, como andares de um prédio. Como em cada uma das áreas há um número de trabalhadores em cada operação, teríamos no total, em cada operação, um múltiplo dos trabalhadores de um andar, tanto maior quanto maior o número de andares sobrepostos. E no prédio total teríamos um grande contingente de trabalhadores. Esta imagem retrata o que ocorre regularmente na indústria e não pode ocorrer na agricultura. 
GERMER, Claus. Estado e questão agrária.

relação entre a massa total dos meios de produção (MP) e o contingente de trabalhadores (FT) empregados, o que resulta na massa de meios de produção por trabalhador ${ }^{21}$. A não simultaneidade das operações, na agricultura, limita a elevação da escala absoluta das unidades, isto é, a área total por unidade, mas limita muito menos a da escala relativa, isto é, a produtividade do trabalho, que depende principalmente da mecanização - tudo o mais permanecendo constante - viabilizada pelos motivos já expostos.

O que é decisivo é que, a um dado nível de desenvolvimento da mecanização, um só ou poucos trabalhadores podem explorar a área correspondente ao equipamento mecânico mais avançado, obtendo a total produtividade do trabalho permitida por este equipamento $^{22}$, uma vez que as operações são sucessivas no tempo, de modo que cada operação pode ser realizada pelos mesmos poucos trabalhadores, cada uma a seu tempo ${ }^{23}$. Como a dimensão física das máquinas, por exemplo, tratores e colhedeiras, não pode aumentar ilimitadamente e o tempo disponível para cada operação também é limitado biologicamente, a escala absoluta da produção que promove a máxima produtividade (expressando a ecala técnica) é também limitada ao que se poderia denominar módulo básico, que corresponde a determinada área, que pode ser erigida em módulo máximo. É óbvio que, inexistindo limitação legal de

${ }^{21}$ Como a massa física de meios de produção não pode ser quantificada, por ser composta por elementos heterogêneos, utiliza-se, como aproximação da composição técnica do capital, a produtividade física do trabalho, isto é, a massa de produtos produzida por trabalhador no tempo dado.

${ }^{22}$ A diferença desta divisão do trabalho em relação à manufatura reside no fato de que, na agricultura atual, como na indústria, as operações parciais não são realizadas pelos próprios trabalhadores, como na manufatura, mas por máquinas, que realizam a maior parte das operações produtivas, sendo apenas acionadas pelos trabalhadores.

${ }^{23}$ Se todas as operações pudessem ser realizadas simultaneamente, como na indústria de transformação, também na agricultura aumentariam os contingentes de trabalhadores acompanhando a ampliação das escalas absolutas de produção. 
GERMER, Claus. Estado e questão agrária.

área, um capitalista pode duplicar ou triplicar, ou multiplicar ainda mais, o seu parque mecânico, de modo a colocar em ação, sob o seu comando único, diversas unidades mecânicas de produção ou módulos básicos ${ }^{24}$. Mas ao mesmo tempo pode-se limitar a dimensão da área explorada à dimensão correspondente à escala mínima - o módulo básico -, restringindo o acesso dos capitalistas agrícolas a uma área desta dimensão, que é o que faz o Estado quando estabelece um limite máximo à área individual, com isto viabilizando a sobrevivência da produção em pequena/média escalas absolutas, isto é, da pequena burguesia rural conservadora e anti-socialista, sem ao mesmo tempo limitar necessariamente a elevação da produtividade do trabalho agrícola ao nível correspondente ao desenvolvimento das forças produtivas da economia como um todo, ou com um comprometimento suportável deste fator, que se pode contabilizar como um dos custos da estabilidade do poder burguês.

Duas restrições devem ser feitas aos motivos da viabilidade da limitação, pelo Estado, da área máxima, expostos acima. A primeira, que é contornável, decorre do desenvolvimento das forças produtivas, por exemplo, o aumento da potência das máquinas agrícolas, que requer aumento da área explorada, ou seja, da escala absoluta e, consequentemente, do módulo básico, definido em lei, o que geralmente ocorre sem problema. Alternativamente o mesmo pode ocorrer através do arrendamento, burlando a lei, como já citado.

A segunda é mais dificilmente contornável, e refere-se à possibilidade de formação de unidades multi-modulares. É provável que unidades multi-modulares alcancem níveis de composição técnica do capital e de produtividade do trabalho mais elevados que as unidades mono-modulares, devido à maior concentração geográfica da produção, à unificação administrativa,

${ }^{24}$ A limitação da área máxima por produtor é amplamente ultrapassada, nos EUA, pelo recurso ao arrendamento, por um produtor, de áreas contíguas de produtores que se retiram da agricultura. 
GERMER, Claus. Estado e questão agrária.

etc, ou seja, devido às vantagens da centralização do capital. Isto sugere que a manutenção de uma estrutura agrícola com predomínio de pequena/média escalas absolutas impõe limites ao aumento da composição técnica do capital e portanto da produtividade do trabalho, em relação ao seu potencial, ao nível das forças produtivas da agricultura em cada momento, constituindo, portanto, um custo imposto ao capital pela aliança burguesa-camponesa. $\mathrm{O}$ fato de que unidades multi-modulares existam nos países capitalistas, devendo ser limitadas pelo Estado, e tenham predominado nos antigos países socialistas, constitui uma forte indicação da superioridade econômica de tais unidades. Sendo isto verdade, a contenção do desenvolvimento das escalas de produção na agricultura capitalista constituiria uma evidência da resistência, apontada por Marx, das relações de produção, isto é, da forma jurídica da propriedade privada, por intermédio dos seus beneficiários - a classe proprietária -, ao desenvolvimento das forças produtivas na direção da socialização. Por este motivo, a experiência de centralização da produção agrícola em larga escala, realizada nos antigos países socialistas, é uma experiência a ser estudada mais detidamente.

\section{Conclusões}

Este artigo procurou apontar a conexão existente entre a questão agrária - expressão de problema enfrentado pelo movimento operário socialista no final do século 19 - e a política agrária do Estado capitalista durante o século 20. Indicou-se que a solução deste problema pelo movimento socialista da Rússia, condição da vitória da revolução, converteu-o em problema para as burguesias dos demais países europeus, cuja solução, por sua vez, consistiu na reorientação da sua estratégia de classe, expressa nas políticas agrárias subsequentes. Mostrou-se que o objetivo central de recuperar o apoio do campesinato traduziu-se na execução de políticas de proteção do mesmo contra o processo de centralização de capital e proletarização. Tais políticas consistiram em assegurar 
GERMER, Claus. Estado e questão agrária.

condições que impedissem a inviabilização econômica das pequenas unidades de produção e sua absorção pelas maiores.

Por outro lado, argumentou-se que, para que tais políticas fossem viáveis, seus efeitos teriam que ser compatíveis com as exigências do restante da economia, ou seja, não poderiam paralizar o desenvolvimento das forças produtivas, associado à elevação das escalas de produção, o que a manutenção de pequenas escalas na agricultura pelas políticas agrícolas parecia contradizer. Mostrou-se que $o$ fato de se terem revelado viáveis, indica a existência de particularidades técnicas da agricultura, que permitem compatibilizar pequenas escalas de produção com o desenvolvimento das forças produtivas, e apontou-se tais particularidades. Isto é possível devido à relativa independência existente entre as escalas absoluta e relativa de produção na agricultura, graças às características biológicas desta, que foram explicitadas.

Finalmente procurou-se indicar que a limitação das escalas absolutas de produção na agricultura, embora não limitem totalmente a elevação das escalas relativas, limitam-nas em alguma extensão, o que significa que limitam a elevação da produtividade do trabalho, o que constitui um custo efetivo da aliança burguesacamponesa.

\section{Referências bibliográficas}

ENGELS, F. A Origem da Família, da Propriedade Privada e do Estado. $6^{\text {a }}$ ed. Rio de Janeiro: Civilização Brasileira, 1980.

FINE, B. Concorrência. In: BOTTOMORE, T. (Ed.) Dicionário do pensamento marxista. 2a. ed. Rio de Janeiro: Jorge Zahar, 1988. p. 74-76.

GERMER, C.M. A irrelevância prática da agricultura 'familiar' para o emprego agrícola. In: Reforma Agrária. v. 31, $\mathrm{n}^{\circ}$ 1, jan/abr, 2002. p. 47-62. 
GERMER, Claus. Estado e questão agrária.

GERMER, C.M. Marx e o papel determinante das forças produtivas na evolução social. In: Crítica Marxista. IFCH, Unicamp, Campinas, n. 29, 2009. p. 75-95.

HIMMELWEIT, S. Exploração. In: BOTTOMORE, T. (Ed.). Dicionário do pensamento marxista. 2a. ed. Rio de Janeiro: Jorge Zahar, 1988. p. 144-145.

KAUTSKY, K. A questão agrária. Rio de Janeiro: Laemmert, 1968.

LÊNIN, V.I. O Desenvolvimento do Capitalismo na Rússia: O Processo de Formação do Mercado Interno para a Grande Indústria. São Paulo: Abril Cultural. 1982.

LÉNINE, V.I. O Estado e a revolução. In: LÉNINE, V.I. Obras Escolhidas em Seis Tomos. Tomo 3. Moscovo: Edições Progresso / Lisboa, Edições "Avante!", 1985.p. 189-289.

ЛЕНИН, В.И. Государство и революция. 1917. Disponível em<https:/www.marxists.org/russkij/lenin/works/lenin007.htm>. Acesso em: 12 nov. 2014.

LOUREIRO, I. A revolução alemã: 1918-1923. São Paulo: Editora UNESP. 2005.

MANFRED, A. A grande revolução francesa. São Paulo: Fulgor. 1966.

MARX, K. Contribuição à crítica da economia política. São Paulo: Martins Fontes, 1977.

MARX, K. O Capital: crítica da economia política. v. I, t. 1. São Paulo: Abril Cultural, 1983.

MARX, K. O Capital: crítica da economia política. v. I, t. 1. São Paulo: Abril Cultural, 1984a. 
GERMER, Claus. Estado e questão agrária.

MARX, K. O Capital: crítica da economia política. v. III, t.1. São Paulo: Abril Cultural, 1984b.

MARX, K. O Capital; crítica da economia política. v. III, t. 2. São Paulo: Abril Cultural, 1985.

MARX, K. Crítica ao programa de Gotha. In: MARX, K. e ENGELS, F. Obras Escolhidas em 3 vol., vol. 2. São Paulo: Editora Alfa-Omega, (s/d). p. 203-225

MARX, K./ENGELS, F. Manifest der Kommunistischen Partei. In: MARX, K./ENGELS, F. Ausgewählte Schriften. v. I. Berlin: Dietz, 1989. p. 14-72. [Manifesto do Partido Comunista].

MOMMSEN, W.J. La Epoca del Imperialismo. 3a. ed. Madrid: Siglo Veintiuno. 1975.

NORTH, D. Zeugen der Permanenten Revolution - Dokumente zur Entwicklungsgeschichte. In: Richard B. Day und Daniel Gaido (Eds). Witnesses to Permanent Revolution: The Documentary Record. Leiden, 2010.2 Disponível em: $<$ http://www.wsws.org/de/articles/2010/06/perm-j26.html $>$. Acesso em: 11 nov. 2014. (2010).

RICARDO, D. Princípios de Economia Política e de Tributação. Lisboa: Fund. Calouste Gulbenkian, 1975.

SMITH, A. A Riqueza das Nações: investigação sobre sua Natureza e suas Causas. v. 1. São Paulo: Abril Cultural, 1983.

SOBOUL, A. A revolução Francesa. São Paulo: DIFEL, (1974). 